\title{
Peste des petits ruminants vaccine and vaccination in India: sharing experience with disease endemic countries
}

\author{
R. P. Singh ${ }^{1} \cdot$ S. K. Bandyopadhyay ${ }^{2}$
}

Received: 20 July 2015/Accepted: 16 September 2015/Published online: 9 October 2015

(C) Indian Virological Society 2015

\begin{abstract}
Peste des petits ruminants, a viral disease of small ruminants, the control of which is important for poverty alleviation and to ensure livelihood security in Asia, Middle East and Africa. In recognition of these issues, we developed and applied vaccine and diagnostics to demonstrate effective control of PPR during preceding 6 years in a sub-population of small ruminants in India. Two south Indian states, namely Andhra Pradesh and Karnataka, strongly indicated possibility of PPR control with more than $90 \%$ reduction in number of reported outbreaks of PPR, mostly through mass vaccination. Similarly, the situation at the national level also demonstrated a decline of more than $75 \%$ in the number of reported outbreaks. Sharing these experiences may motivate other countries for similar initiatives leading to progressive control of PPR, which is in line with the initiatives of the organizations like FAO/OIE and the recent platforms on global PPR research alliance.
\end{abstract}

Keywords Control - Diagnostic $\cdot$ Eradication $\cdot$ Peste des petits ruminants $\cdot$ PPR $\cdot$ Seromonitoring ·

Serosurveillance $\cdot$ Vaccines

R. P. Singh

rpsingh@ivri.res.in; rpsingh@dr.com

1 Division of Biological Products, ICAR-Indian Veterinary Research Institute, Izatnagar 243122, India

2 Agricultural Scientist Recruitment Board, KAB-1, Pusa, New Delhi 110012, India

\section{Introduction}

Peste des Petits Ruminants (PPR), commonly known as goat plague, is a highly contagious transboundary animal disease of small ruminants caused by a Morbillivirus, under the family Paramyxoviridae. The disease is clinically characterized by high fever, depression and loss of appetite, followed by eye and nose discharges, erosive mouth lesions, pneumonia and severe diarrhea. Many animals in a flock can be affected at the same time and high percentage of these may die. PPR is an important killer disease for small ruminant populations, e.g., sheep and goat. The disease is endemic in several countries of Asia, Middle East and Africa. About $62.5 \%$ populations of total small ruminants are at risk due to PPR globally [18]. Some of the countries have initiated PPR control measures either through their own resources or with the help of other developmental agencies interested in poverty alleviation through improved livestock health and production in general and small ruminant production in particular (http:// www.oie.int/for-the-media/press-releases/detail/article/oielaunches-pilot-project-to-design-efficient-control-methodsfor-peste-des-petits-ruminants-a-dev/). India is one such example, which gathered base line information on disease situation [30], took comprehensive steps through its own internal resources, competence and indigenously developed tools for the control of PPR [28]. These tools include a potent live-attenuated PPR vaccine [36] and monoclonal antibody based diagnostics both for antibody and antigen detection [31, 32]. The findings on initial focused vaccinations followed by mass vaccinations in selected states of India (Andhra Pradesh and Karnataka) have shown a significant decline in PPR outbreaks. Even though, there is a possibility of inadequate disease reporting as is probably the case with several other countries, a decline of more 
than $75 \%$ outbreaks from amongst the reported outbreaks between the year 2005 to 2013 [29] was observed in India (http://www.oie.int/wahis_2/public/wahid.php/Diseaseinformation/statusdetail). The recent trends of PPR outbreaks in India indicate that the progress beyond this level of control is becoming difficult and further progress cannot be made until and unless an organized mass vaccination campaign is launched to break the epidemiological cycle in the entire country. Being a trans-boundary animal disease, reducing the threat of re-incursion of PPR from the neighboring endemic countries due to inadequate border control, would also require a regional programme and a common action plan by all the stakeholders for an efficient control of the disease and its subsequent eradication. The initiatives already taken by the Food and Agriculture Organization (FAO) through South Asian Association for Regional Cooperation (SAARC) and its Regional Support Unit (RSU) are already progressing along those lines, which need to be strengthened further (http://www.saarc-rsu-hped.org/ content/reports/2013-12-19Second_regional_workshop_on_ progressive_control_of_PPR-Ktm-Nepal.pdf).

The objective of the present report is to share the Indian experiences of use of the indigenously available vaccines, diagnostics and modalities for the control of PPR with other endemic countries at large. This information becomes even more relevant when the Asian lineage (Lineage IV) PPR virus is spreading fast to several parts of African continent besides Asia [1, 18] and eroding the perception of lineage segregation of PPR virus between continents as reported earlier $[9,15]$.

\section{Epidemiology of PPR in India during the last decade}

PPR was reported for the first time in India in the year 1987 from southern part of the country [26]. The disease was apparently confined to the southern part of the country only, with the emergence and spread of PPR virus in Westand South Asia in 1994, PPR became endemic in entire India and its neighboring countries [9]. Large scale outbreaks became visible, when indigenously developed diagnostic kits were extensively applied for field diagnosis [30]. Distribution of 3131 reported outbreaks between the year 2005-2013 indicated that the disease is prevalent in almost all the states/parts of India (Fig. 1) except a few north-eastern states, which are relatively isolated from the main land and are also having fewer small ruminants [30]. Although surrounded by two affected states in its eastern and northern borders, one small southern state of India, namely Kerala have not reported the presence PPR till now. Among plausible reasons for this somewhat unusual epidemiological feat could be, much less number of small ruminants present in the state compared to its neighbours and failure to detect PPR disease due to low impact of such sporadic disease events in small ruminants. The intensity of the PPR outbreaks during the last 9 years was relatively more in the areas with high population density of small ruminants [28]. This explains the higher possibility of disease transmission linked to intermixing of the animals. In some parts of the country, transhumance also contributes to the spread of the disease particularly in the arid region of western India extending up to the Himalayan cold desert areas [28].

A sero-prevalence study conducted between the years 1998 to 2003 with about 4407 serum samples indicated $33 \%$ prevalence of PPR virus antibodies among susceptible small ruminant population in India [30]. A subsequent study with about 4884 samples between the years 2003 to 2009 demonstrated an average antibody prevalence of $43.56 \%$ [5]. During the later period of the study, vaccination against PPR has already begun in several parts of the country though not always in a very organized manner. Since the sero-monitoring/surveillance kit used in the study [31], does not differentiate post-vaccination and convalescent antibodies, it is probable that a lot of samples in the later study may have been drawn from vaccinated population, particularly from the states which started the campaign early. As a result, blood serum samples are often referred to diagnostic laboratories for detection of PPR antibodies without specifying the objective, i.e., sero-monitoring or sero-prevalence or simply for disease diagnosis. A lot of focused/strategic vaccinations were done during the year 2007-2011 using a vaccine, which produces detectable antibodies for long duration [24]. However, neither a systematic sero-monitoring programme was initiated during the last decade to assess the efficacy of the vaccination campaign nor any sero-surveillance plan was taken up particularly in the unvaccinated areas to estimate the prevalence. In the absence of such systematic sero-surveillance as well as limited epidemiological data on the disease so far in the country, large-scale vaccination had not produced the desired impact in the country except an overall and visible reduction in the number of disease outbreaks. However, clinical surveillance is considered to be an important indicator for measurement of success of a vaccination campaign leading to disease control as observed during the rinderpest eradication programme. In a systematic control programme, strategic surveillance plans will have to be designed and implemented to demonstrably prove the impact of the control programme. Differentiation of infected and vaccinated animals (DIVA) enabled vaccines and diagnostics could be very useful in such a scheme. 
Fig. 1 Map showing the intensity/distribution of 3131 reported PPR outbreaks of small ruminants in various Indian states/administrative units during last 9 years (year 2005-2013). States with international porous borders are also indicated on the map

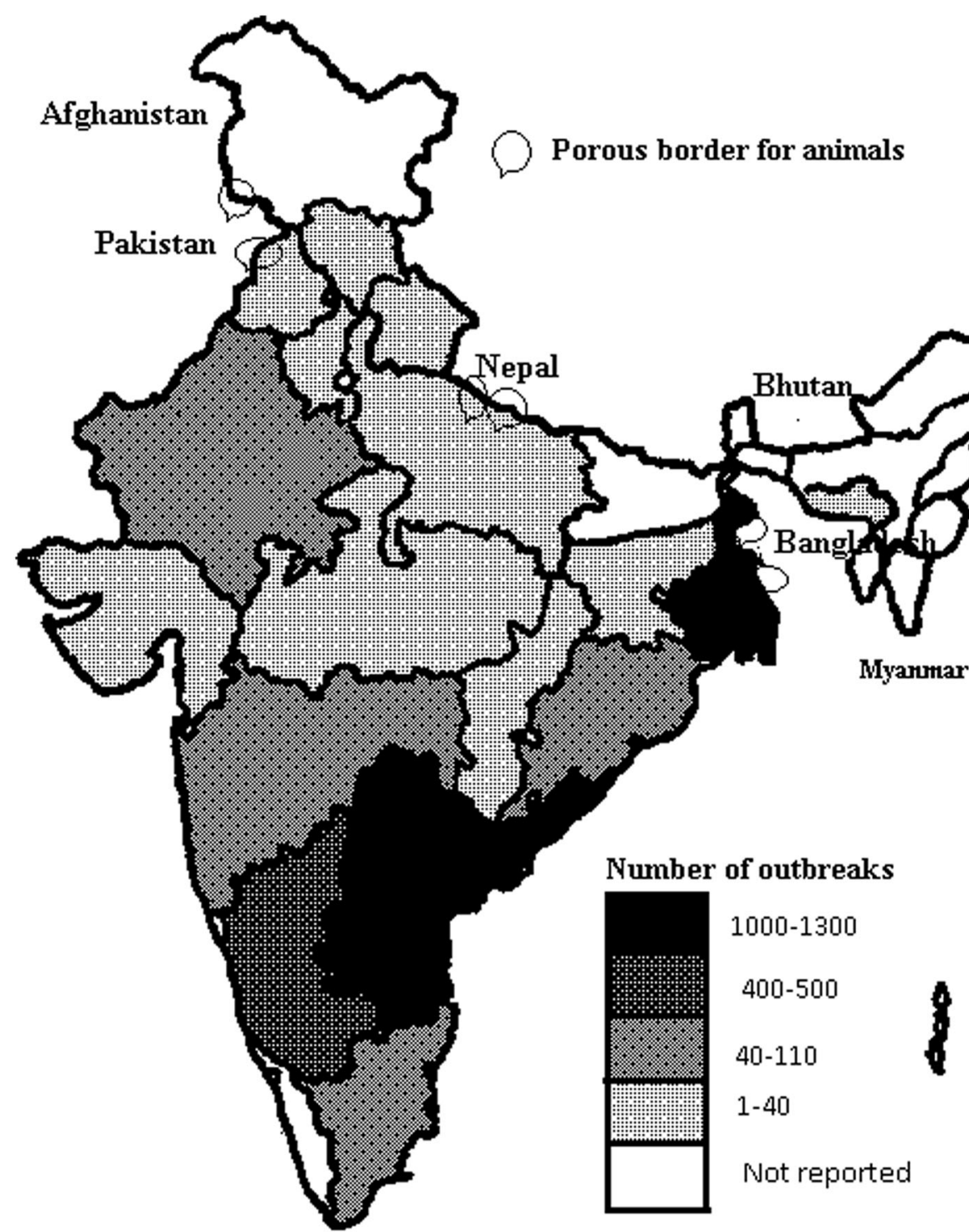

9

\section{Available tools (vaccines and diagnostics) for control of PPR in India}

\section{PPRV-Sungri/96 vaccine virus}

PPRV/Sungri/96 strain [36] is the only vaccine virus strain used in India under mass PPR vaccination campaigns as all the commercial manufacturers in India, both at private and public sectors, are currently using only this Lineage IV virus. This vaccine virus has been characterized extensively both at the antigenic level and at genomic level. Characterization included antigenic profiling using a panel of 23 mouse monoclonal antibodies raised against PPR virus and comparison with other virus isolates from different parts of the country $[33,35]$. Thermo-stability of the vaccine [25], duration of immunity [24] and antigenic profile [35] were studied extensively. The long term immunity study indicated that the vaccine induces and maintains optimum virus neutralizing antibodies for long duration [24]. Therefore, a single-dose immunization protocol is sufficient for protection of small ruminants. Entire genome of this Asian lineage vaccine virus has been sequenced [27]. Detailed comparative analysis of different genes of this vaccine virus is available in public domain [10, 21, 22]. Further, in order to increase the utility of PPR vaccine virus and to reduce the cost of vaccinations for the control of three important viral diseases of small ruminants, both sheep pox vaccine and goatpox vaccine have been used as combined vaccines with PPRV/sungri-96 Vaccine virus with encouraging results and field applications $[8$, 
13]. These efforts are important for poverty alleviation programmes for livestock rearing in Asia and Africa through improved small ruminant disease control strategies. Large scale application of this PPR vaccine to control the disease in India has been largely possible due to a Government of India supported PPR Control Programme throughout the country [2].

In order to make the PPR vaccine easily available to all the stakeholders in India, the PPRV/Sungri 96 vaccine virus, along with production and quality control technology has been transferred to commercial manufacturers in the public and private sectors for large-scale production and supply. Due to simplicity of technology (1 ml of vaccine virus harvest yields about 100-500 OIE-recommended doses) the vaccine manufacturers in India are now capable to meet both the internal demand and to export PPR vaccine to meet the demand in South Asia, Middle-East and Africa.

\section{Validation/characterization of PPR diagnostics developed in India}

The monoclonal antibody based diagnostic tests namely sandwich-ELISA and competitive-ELISA [31, 32] developed by us have been validated extensively with a large sample size using standard tests such as virus neutralization test and similar commercial diagnostic kits available [16, 17]. Diagnostic sensitivity and specificity of ELISA kits developed by us were comparable to international gold standards. These kits have been used within the country for diagnosis since almost last 10 years. Further validation of these kits with the help of the World Reference Laboratory of PPR, will allow its large scale application during any global control programme for eradication of PPR similar to that of the successful OIE/FAO Global Rinderpest Eradication Programme. Subsequently, these ELISA tests have been used as gold standard tests for development and comparison of several other tests. These include use of competitive ELISA for comparison with indirect ELISA for PPR antibody detection [4], sandwich ELISA test for comparison with PCR ELISA [23] and PCR assays [3, 12] to detect PPR virus.

\section{Impact of vaccine and vaccination in selected states of India using indigenous tools}

Sharing of success stories is an interesting tool to extend a composite solution to a complex problem. Application of the available tools (vaccines and diagnostics) and strategies gave a clear indication that PPR vaccine used under mass vaccination campaign can provide solid immunity leading to reduction of more than $95 \%$ outbreaks in selected states pursuing continuous strategic vaccination. Success story of
Andhra Pradesh state on India indicates that this administrative unit was continuously reporting 300-500 PPR outbreaks during the year 2002-2003 to 2005-2006 (http:// www.oie.int/wahis_2/public/wahid.php/Diseaseinformation/ statusdetail). Focused vaccination to contain the outbreak followed by two cycles of intermittent mass vaccination and selective vaccinations of unvaccinated lambs/kids above 5 months age reduced the epidemic level to more than $95 \%$ (Table 1; Fig. 2a). The recommended age for vaccination with this vaccine has been estimated to be 5 months and above as the maternal antibodies from vaccinated dams wane by about 4 months [6]. The flock/herd immunity in vaccinated animals ranged between 81-95.6\%. Similarly a success story from Karnataka state, which was reporting outbreaks between 60-142 in the years 2005/06 to 2007/08, came down to a level of 1-3 reported outbreaks in the year 2011-2012 (Fig. 2b) following mass vaccination campaign in the target population (http://www.oie.int/wahis_2/public/ wahid.php/Diseaseinformation/statusdetail). These two Indian states, i.e., Andhra Pradesh and Karnataka, have a population of 35 million and 15.6 million (total of 50.6 million) small ruminants respectively, as per the Government of India Livestock Census, 2007 (http://dahd.nic.in/ dahd/statistics/animal-husbandry-statistics.aspx).

Trend of PPR outbreaks at the national level was similar to the trend as observed in Karnataka and Andhra Pradesh states indicating a decline of about $80 \%$ outbreaks (165-247 outbreaks between the year 2009/10-2012/13 as compared to 1071 (Fig. 2c) outbreaks during 2005-2006) (http://www.oie.int/wahis_2/public/wahid.php/Diseaseinformation/statusdetail). However, there was no further definite declining trend during the last 4 year (year 2009/10-2012/ 13) at the national level. This observation indicates that the mass vaccinations at national level was not as rigorous as in the states of Andhra Pradesh and Karnataka and the initiatives and the resources made available, varied between the states. During the last 5 year plan (year 2007-2012) Government of India initiated PPR control programme in five selected administrative units/states. The states with good financial support, human resource and commitment demonstrated better progress in PPR control as compared to other administrative units. This was taken as pilot programme of Government of India, wherein all other states were also provided partial financial support. Although, the control and eradication of PPR seems to be an achievable goal, in a federal system of governance as in India, zonal and regional control programmes may be necessary within the country to achieve step-wise milestones of success while making constant efforts to reduce the number of outbreaks in the still-happening zones. Special efforts will also be needed in those administrative units having international boundaries with the neighboring countries through creation of an effective immune belt, close monitoring at the borders as 
Table 1 Strategies followed for immunization/vaccination by state of Andhra Pradesh for PPR control and its impact on the number of outbreaks over a period of time

\begin{tabular}{|c|c|c|c|c|c|}
\hline Year & $\begin{array}{l}\text { No of out } \\
\text { breaks (OIE, } \\
2014)\end{array}$ & $\begin{array}{l}\text { Annual vaccine } \\
\text { supplies (million } \\
\text { doses) }\end{array}$ & $\begin{array}{l}\text { Cumulative vaccine coverage } \\
\text { during preceding } 3 \text { years } \\
\text { (millions) }\end{array}$ & Vaccination strategy & $\begin{array}{l}\text { Flock/herd immunity } \\
\text { (using competitive- } \\
\text { ELISA) }\end{array}$ \\
\hline 2005-2006 & 290 & 9.0 & 9.0 & Focused & ND \\
\hline $2006-2007$ & 130 & 10.0 & 19.0 & Focused & ND \\
\hline $2007-2008$ & 113 & 16.0 & 35.0 & Mass vaccination & 81.1 \\
\hline 2008-2009 & 30 & 8.0 & 34.0 & $\begin{array}{l}\text { Young ones above } 5 \text { months } \\
\text { and unvaccinated goat and } \\
\text { sheep }\end{array}$ & ND \\
\hline 2009-2010 & 10 & 8.0 & 32.0 & $\begin{array}{l}\text { Young ones above } 5 \text { months } \\
\text { and unvaccinated goat and } \\
\text { sheep }\end{array}$ & ND \\
\hline 2010-2011 & 24 & 10.5 & 26.5 & Mass vaccination & 95.6 \\
\hline 2011-2012 & 01 & 14.0 & 32.5 & $\begin{array}{l}\text { Young ones above } 5 \text { months } \\
\text { and unvaccinated goat and } \\
\text { sheep }\end{array}$ & 91.0 \\
\hline 2012-2013 & 01 & 9.0 & 33.5 & $\begin{array}{l}\text { Young ones above } 5 \text { months } \\
\text { and unvaccinated goat and } \\
\text { sheep }\end{array}$ & 89.5 \\
\hline
\end{tabular}

$N D$ not done

well as enhanced vaccination campaigns. In addition, a regional cooperation, in line with the OIE/FAO global strategy, to ensure progressive control of PPR (PC-PPR) in the neighboring countries, will help to solve the problem globally as it is an important transboundary animal disease (http://www.saarc-rsu-hped.org/content/reports/2013-12-19 Second_regional_workshop_on_progressive_control_of_ PPR-Ktm-Nepal.pdf). The efforts and achievements in Andhra Pradesh and Karnataka reaffirms that PPR is yet another disease, which is possible to control with programmes similar to rinderpest. Smaller countries in Asia and Africa, with small ruminant population somewhat similar to these two states (total of 50.6 million small ruminants) can be motivated with the success stories of these two Indian states. It is worthwhile to mention here that the total small ruminant population of several Asian and African countries would be equal or less than these two Indian states individually (http://faostat.fao.org/site/ 573/DesktopDefault.aspx\#ancor).

Government of India, initiated a phase-wise PPR control programme with intensive vaccination in a few selected states during its five-yearly plan covering the period 2007-2011 and with the partial support for vaccination to the remaining states. The states/administrative regions with intensive efforts on PPR vaccination have demonstrated a strong decline in the incidence of PPR. This situation needs to be created and replicated in all the other states of India through intensive vaccination during the current 5 year plan (year 2012-2017). A simplified vaccination strategy under different geo-spatial situations depending upon the availability of vaccine is also presented (Table 2).

\section{Advocacy and communication strategies for PPR control in India}

Creating public awareness is an integral component of any successful disease control programme. Main source of funding the PPR control programme in India is the Department of Animal Husbandry, Dairying and Fisheries (DAHDF). Similarly the agency responsible for research and development for PPR vaccine and diagnostics is the Indian Council of Agricultural Research (ICAR). Both these agencies are under the overall control of the Ministry of Agriculture, Government of India for a better coordination, co-operation and communication at the national level. ICAR is the major source of knowledge bank and technical support for PPR control in India. The implementation of the vaccination or the control programme lies within the domain of the local administration of the concerned states through their veterinary and administrative machinery. In addition, veterinary universities/schools located in almost each state of the country are very important knowledge pool, supporting both to ICAR through research projects and state animal husbandry departments by guidance on execution of the disease control programs. Therefore, these organizations act as an important links between, central government 

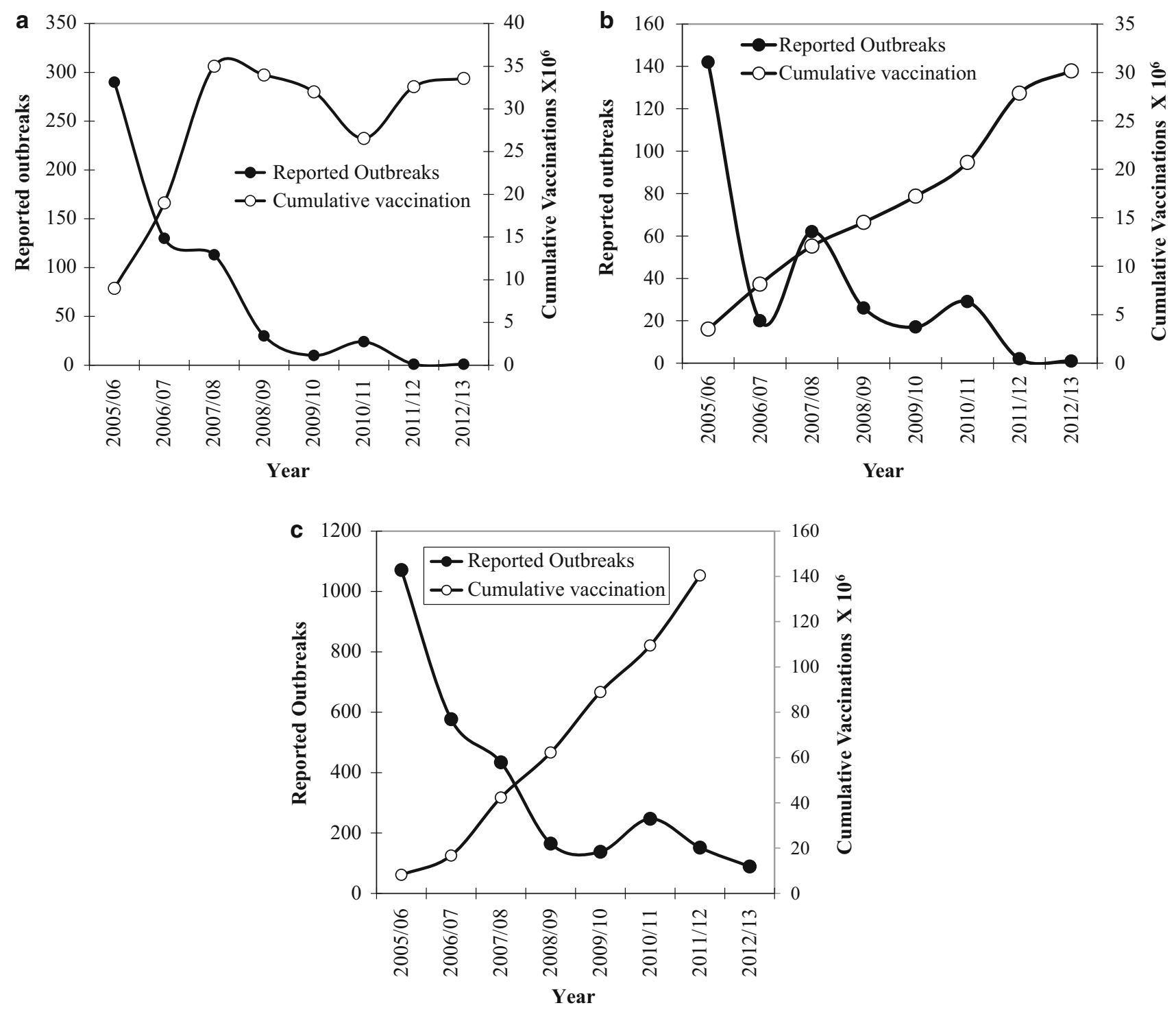

Fig. 2 Trend of reduction of PPR outbreaks in the state of Andhra Pradesh (a), Karnataka (b) and the whole of India (c) during the year from 2005 to 2012 based on the reports from Government of India to OIE (Y1 axis). Note that the cumulative doses of vaccines used during

departments in Ministry of Agriculture, Government of India and the state animal husbandry departments. The efficacy of the vaccination programme is therefore dependent upon the coordination between various authorities at the national, regional (states), sub-regional (districts) to the lowest administrative units, referred to as a 'block' comprising a group of villages. Our experiences indicate that there is a need for greater coordination for a PPR control programme to yield the desired result even though the resources for the control programme, e.g., financial and technical, are adequately available. Also, for higher acceptance of the program amongst the public, there is a need for involvement of community level/ the preceding 3 years are also depicted (Y2 axis) as the vaccine produces immunity for 6 years and strategic immunizations were carried out

village level animal health workers during mass vaccinations as well as for accurate reporting of the disease. Such awareness among livestock farmers, particularly those in small and subsistence farming could be useful for monitoring and reporting of other endemic or sporadic diseases, e.g., FMD or Avian Influenza. Further, strong network of information and communication technologies (ICT) and also infrastructure, which were not available during rinderpest control programme are available now for disease reporting. In order to enhance disease reporting, the government of India has now created an online disease surveillance and reporting network portal through a centrally supported programme named as "National 
Table 2 A simplified vaccination strategy for control of PPR

\begin{tabular}{|c|c|c|}
\hline $\begin{array}{l}\text { Sl. } \\
\text { no. }\end{array}$ & Situations on quantity of vaccine available & PPR vaccination strategy \\
\hline 1. & Limited doses of vaccine is available & $\begin{array}{l}\text { Vaccinate high risk group animals (goat and sheep) such as nomadic flocks, young } \\
\text { animals below } 1 \text { year of age, animals which are subject to intermixing with other } \\
\text { animals. Ring vaccination to control outbreaks. A good quality vaccine using a } \\
\text { minimum of } 10^{2.5} \text { TCID }_{50} \text { of vaccine virus/animal to be used subcutaneously }\end{array}$ \\
\hline \multirow[t]{6}{*}{2.} & \multirow{6}{*}{$\begin{array}{l}\text { Sufficient doses of vaccines are available for } \\
\text { disease control continuously }\end{array}$} & Ist year: vaccinate all sheep and goat above 5 months \\
\hline & & $\begin{array}{l}\text { IInd year: vaccinate all un-vaccinated sheep and goat and new born lambs and kids } \\
\text { above } 5 \text { months }\end{array}$ \\
\hline & & $\begin{array}{l}\text { IIIrd year: vaccinate all un-vaccinated sheep and goat and new born lambs and kids } \\
\text { above } 5 \text { months }\end{array}$ \\
\hline & & IVth year: vaccinate all sheep and goat above 5 months \\
\hline & & $\begin{array}{l}\text { Vth year: vaccinate all un-vaccinated sheep and goat and new born lambs and kids } \\
\text { above } 5 \text { months }\end{array}$ \\
\hline & & $\begin{array}{l}\text { VIth year: vaccinate un-vaccinated sheep and goat and new born lambs and kids above } \\
5 \text { months }\end{array}$ \\
\hline 3. & Adlib vaccines available for disease eradication & $\begin{array}{l}\text { Carpet vaccination for } 5 \text { years (vaccinate all sheep and goat above } 5 \text { months for } \\
5 \text { years). And maintain immune belt to check any infiltration from out side }\end{array}$ \\
\hline
\end{tabular}

Animal Disease Reporting System" (http//:www.nadrs. gov.in/SitePages/Home_NADRS.aspx).

\section{Socio-economic studies}

A preliminary study indicated that the annual losses due to PPR in India are to the tune of INR 1800 million or USD 39 million [7]. These estimates were done during the year 2001-2002, when level of PPR outbreaks observed were at very low rate, using a limited number of imported PPR diagnostic kits. Subsequently, with the increase in number of reported out breaks (from 150 outbreaks to about 600 outbreaks) in the year 2003 and 2004 [28], these losses could have been around USD 400 million with the escalated associated cost including food price inflation. Subsequently though with the application of appropriate diagnostic tools as well as improvement in the disease reporting, the annual losses were estimated to have reached up to USD 1308.78 million at the peak of outbreaks as observed during 2005 [34]. Initial reduction in the number of outbreaks at national level by about $80 \%$ indicates that the losses could be reduced to the tune of USD 1047 million/annum (INR 62820 million/annum) due to the measures adopted to control PPR including limited mass vaccination campaigns. However, actual benefits could be several folds higher if we also factor in the recovery from indirect losses, e.g., increased export potential, regaining livelihood, etc. Our observations also suggest that it is possible to reach to a minimum number of outbreaks (about $99 \%$ reduction from here onward) within a span of 6 years if we adopt strategic vaccinations. This will include two cycles of vaccination, each including annual mass vaccination followed by vaccination of unvaccinated and newborn lambs and kids at the age of 5 months and beyond for 2 years, as has been practiced by the state of Andhra Pradesh. This level of reduction (99\%) may be possible even before 6 years if we go for annual mass/carpet vaccinations in all the states and if resources are available. In our opinion, there is irrefutable evidence now in India that control of PPR with ultimate objective of eradication is possible and this should be taken up in right earnest under the sustainable development plank of food security and poverty alleviation.

\section{Challenges and possible solutions for PPR eradication}

Authors feel that there are some possible challenges for eradication of PPR in India and also in other endemic countries. These challenges include availability of quality vaccines, thermo labile nature of the currently available vaccine, highly dynamic population of goat and sheep due to high prolificacy of goats, mass movement with particular reference to the stock with the trans-human tribes, lax border control at both intra and international borders, incomplete understanding of the epidemiological cycle of the disease or the emergence of any other morbilli viruses of small ruminants. The main threat of PPR incursion from international borders is through non-defined and informal trade routes especially at the border points with Nepal, Bangladesh and Bhutan as these countries share a lot of socio-cultural relations with India. These problems could 
be solved only through regional co-operation. SAARCRSU/FAO can play a pivotal role to strengthen progressive control of PPR at par in all the neighboring countries (http://www.saarc-rsu-hped.org/content/reports/2013-12-19 Second_regional_workshop_on_progressive_control_of_ PPR-Ktm-Nepal.pdf). Small ruminant based nomadism has already been reported in arid regions of Rajasthan and also in sub Himalayan cold desert region (Uttarakhand, Himachal Pradesh, Jammu and Kashmir) where there are mass bi-seasonal movements of flocks of sheep and goats in search of water and pasture [28, 30]. These factors may lead to non-sustainable herd/flock immunity in sheep and goat, unlike for rinderpest in cattle and buffaloes with relatively stable population dynamics due to long life span.

Even though, disease control in primary host is important, the other hosts mainly wild ungulates, which may harbor the virus may be important too from the point of view of disease eradication. These include, Defassa waterbuck (Kobus defassa) Kob (Kobus kob), Laristan sheep (Ovis gmelini laristanica) Nubian Ibex (Capra nubiana), Gemsbok (Oryx gazelle), Dorcas gazelle (Gazella dorcas), Thompson's gazelle (Eudorcas thomsonii), Springbuck (Antidorcas marsupialis), Arabian mountain gazelle (Gazella gazella cora), Arabian gazelle (Gazella gazelle) Rheem gazelle (Gazella subguttorosa marica), Bushbuck (Tragelaphus scriptus) Impala (Aepyceros melampus), Goitered gazelle (Gazella subgutturosa subgutturosa), Bharal (Pseudois nayaur), Sindh Ibex (Capra aegagrus blythi). PPR virus or virus specific antibodies in these species have been reported from various parts of Africa, Arabian peninsula and Asia [19]. Experiences with rinderpest eradication show that wild life may not pose hurdle for disease eradication once it is controlled in the primary host. Keeping in mind that PPR is not rinderpest and that small ruminants are not cattle and buffalo, wild life population (specially wild ungulates) may pose some hurdle in final stages of eradication of PPR in India and other endemic countries as well.

A vaccination strategy for achieving PPR control has been defined [28]. Using a similar strategy, the state of Andhra Pradesh with a population of about 35 million sheep and goat was able to reduce the burden of outbreaks by about $99 \%$ (one reported outbreak in 2011-2012 and 2012-2013 as against about 300 outbreaks in the year 2005-2006). From the analysis of the data available so far after the strategic campaigns launched in selected states of India, it is evident that control of PPR is possible in the country. However, its eradication from a geographically defined area may require a sustained effort and regional cooperation. To reduce the problem of thermo-stability, vaccinations during the winter season can be advocated. Also looking at the dynamic nature of the animal population in the country, vaccination of new born lambs and kids above 5 months age can be practiced every year followed by mass vaccination/carpet vaccination of all small ruminants above 5 month age every 3 years. During the subsequent years, mass vaccination of target population (above 5 months), creation of immune belts at the borders, targeted sero-surveillance will be the required strategies to be employed before the final push for eradication. Pulse vaccinations, that means vaccination in the shortest possible time for all sheep and goats, within 30 days, is also an important tool for blocking the epidemic cycle of PPR.

Availability of a marker vaccine against PPR along with associated diagnostic tools may further ease the PPR eradication programme both in India and also at the global level. This strategy targets vaccination of small ruminants using a marker vaccine for differentiation of vaccinated animals and infected animals (DIVA) by use of an appropriate diagnostic tool. The strategy is important especially for epidemiological surveillance programme based on serology. Further, development of recombinant PPR vaccines and virus like particles which are relatively more thermostable and have DIVA capability through use of companion diagnostic tests are required for effective control of the disease and to reduce the cost and time of eradication. The veterinary institutes/ schools/universities and their faculties can play an important role in development of such vaccines and companion diagnostics. The efforts, in this direction have already been initiated globally $[14,20]$.

\section{Conclusions}

Authors are of the opinion that at least one country in each of the African and Asian continent should establish a strategic model for control and eradication of PPR using the vaccine derived from African [11] or Asian lineage [36] vaccine viruses. The efforts in India are part of such initiatives using an indigenously developed vaccine. Countries in Africa namely Ethiopia, Nigeria and Kenya have launched similar initiatives with the help of other international funding agencies (http://www.oie.int/for-the-media/ press-releases/detail/article/oie-launches-pilot-project-todesign-efficient-control-methods-for-peste-des-petits-rumi nants-a-dev/) for PPR control. It seems, Asian region has more indigenously developed tools and techniques, whereas, African region has strength in public awareness and coordination mechanism for initiating an effective PPR control and eradication programme. Combining the comparative strengths of both these regions may lead to a faster progress in PPR control and eradication at the global level. Such an initiative needs to be overseen by International Agencies like FAO/OIE and GPRA. 
Strategies for the progressive control of PPR as adapted by some of the selected Indian states described here are recommended to be adapted by all the endemic countries. The two important vaccines developed and being used widely incorporating lineage-II [11] and lineage IV [36] PPR viruses may lead to reduction of PPR in the globe to the tune of $99 \%$ in next 5 years if applied to the level to that of two Indian states of Andhra Pradesh and Karnataka have adapted. Even with a variable application, we may achieve a situation with more than $75 \%$ reduction as is the case with national picture in case of India. It is possible that all the countries may not be in a situation to execute PPR control programme at equal level due to one or the other reasons (difference in economies, civil unrest) [30]. Even with the $75 \%$ reduction in the number of outbreaks, the endemic countries based on the goat and sheep population at risk, may be able to save economic losses to the tune USD 5635 million/annum. These figures have been derived based on the figures as shown for India due to $75 \%$ reduction in outbreaks on 210 million small ruminant populations as against about 1127 million globally at risk to PPR (http://www.fao.org/ag/againfo/ resources/documents/AH/PPR_flyer.pdf). With the successful control on PPR due to strategic vaccinations in the next 5 years, we may reach to a stage, where Global PPR Eradication Programme, targeted to be accomplished by the year 2030, will appear to be a reality. During this stage, both sero-monitoring and sero-surveillance becomes essential to monitor effectiveness of vaccine and also disease incidences. In such a scenario, the next 5 years are also important for capacity building in respect of PPR vaccine manufacturing, careful use under field conditions and preparations related to monitoring of successful vaccinations.

Acknowledgments Authors are thankful to the Animal Husbandry Department of Andhra Pradesh for details of strategies used in state of Andhra Pradesh to control PPR.

\section{References}

1. Albina E, Kwiatek O, Minet C, Lancelot R, de Almeida SR, Libeau G. Peste des petits ruminants, the next eradicated animal disease. Vet Microbiol. 2013;165:38-44.

2. Annual report 2012-2013. Department of Animal Husbandary Dairying and Fisheries, Ministry of Agriculture, Government of India. 2013.

3. Balamurugan V, Sen A, Saravanan P, Singh RP, Singh RK, Rasool TJ, Bandyopadhyay SK. One-step multiplex RT-PCR assay for the detection of peste-des-petits-ruminants virus in clinical samples. Vet Res Commun. 2006;30:655-66.

4. Balamurugan V, Singh RP, Saravanan P, Sen A, Sarkar J, Sahay B, Rasool TJ, Singh RK. Development of an indirect ELISA for the detection of antibodies against peste des petits ruminant's virus in small ruminants. Vet Res Commun. 2007;31:355-64.

5. Balamurugan V, Saravanan P, Sen A, Rajak KK, Bhanuprakash V, Krishnamoorthy P, Singh RK. Sero-epidemiological study of peste des petits ruminants in sheep and goats in India between 2003 and 2009. Rev Sci Tech Off Int Epizoot. 2011;30:889-96.

6. Balamurugan V, Sen A, Venkatesan G, Rajak KK, Bhanuprakash V, Singh RK. Study on passive immunity: time of vaccination in kids born to goats vaccinated against peste des petits ruminants. Virol Sin. 2012;27:228-33.

7. Bandyopadhyay SK. The economic appraisal of a PPR control programme in India. Presented at: 14th annual conference and national seminar on management of viral diseases with emphasis on global trade and WTO regime, Indian Virological Society. Bangalore, India. 2002.

8. Chaudhary SS, Pandey KD, Singh RP, Verma PC, Gupta PK. A vero cell derived combined vaccine against sheep pox and peste des petits ruminants for sheep. Vaccine. 2009;27:2548-53.

9. Dhar P, Sreenivasa BP, Barrett T, Corteyn M, Singh RP, Bandyopadhyay SK. Recent epidemiology of peste des petits ruminants virus (PPRV). Vet Microbiol. 2002;88:153-9.

10. Dhar P, Muthuchelvan D, Sanyal A, Kaul R, Singh RP, Singh RK, Bandyopadhyay SK. Sequence analysis of the haemagglutinin and fusion protein genes of peste-des-petits ruminants vaccine virus of Indian origin. Virus Genes. 2006;32:71-8.

11. Diallo A, Taylor WP, Lefèvre PC, Provost A. Attenuation d'une souche de virus de la peste des petits ruminants: candidat pour un vaccine homologue vivant. Rev Elev Med Vet Pays Trop. 1989;42:311-9.

12. George A, Dhar P, Sreenivasa BP, Singh RP, Bandyopadhyay SK. The $\mathrm{M}$ and $\mathrm{N}$ gene-based simplex and multiplex PCR are better than the F or $\mathrm{H}$ gene based simplex PCR for peste des petits ruminants virus. Acta Virol. 2006;50:217-22.

13. Hosamani M, Singh SK, Mondal B, Sen A, Bhanuprakash V, Bandyopadhyay SK, Yadav MP, Singh RK. A bivalent vaccine against goat pox and peste des petits ruminants induces protective immune response in goats. Vaccine. 2006;24:6058-64.

14. Hu Q, Chen W, Huang K, Baron MD, Bu Z. Rescue of recombinant peste des petits ruminants virus: creation of a GFP-expressing virus and application in rapid virus neutralization test. Vet Res. 2012;2(43):48.

15. Kwiatek O, Minet C, Grillet C, Hurard C, Carlsson E, Karimov B, Albina E, Diallo A, Libeau G. Peste des petits ruminants (PPR) outbreak in Tajikistan. J Comp Pathol. 2007;136:111-9.

16. Libeau G, Diallo A, Colas F, Guerre L. Rapid differential diagnosis of rinderpest and peste des petits ruminants using an immunocapture ELISA. Vet Rec. 1994;134:300-4.

17. Libeau G, Prehaud C, Lancelot R, Colas F, Guerre L, Bishop DH, Diallo A. Development of a competitive ELISA for detecting antibodies to the peste des petits ruminants virus using a recombinant nucleoprotein. Res Vet Sci. 1995;58:50-5.

18. Libeau G, Diallo A, Parida S. Evolutionary genetics underlying the spread of peste des petits ruminants virus. Anim Front. 2014;4:14-20.

19. Munir M. Role of wild small ruminants in the epidemiology of peste des petits ruminants. Transbound Emerg Dis. doi:10.1111/ tbed.12052.2013.

20. Muniraju M, Mahapatra M, Buczkowski H, Batten C, Banyard AC, Parida S. Rescue of a vaccine strain of peste des petits ruminants virus: in vivo evaluation and comparison with standard vaccine. Vaccine. 2015;33:465-71.

21. Muthuchelvan D, Sanyal A, Singh RP, Hemadri D, Sen A, Sreenivasa BP, Singh RK, Bandyopadhyay SK. Comparative sequence analysis of the large polymerase protein $(\mathrm{L})$ gene of peste-des-petits ruminants (PPR) vaccine virus of Indian origin. Arch Virol. 2005;150:2467-81.

22. Muthuchelvan D, Sanyal A, Sreenivasa BP, Saravanan P, Dhar P, Singh RP, Singh RK, Bandyopadhyay SK. Analysis of the matrix protein gene of the Asian lineage of peste-des petits ruminants vaccine virus. Vet Microbiol. 2006;113:83-7. 
23. Saravanan P, Singh RP, Balamurgan V, Dhar P, Sreenivasa BP, Muthuchelvan D, Sen A, Aleyay AG, Singh RK, Bandyopadhyay SK. Development of a N gene-based PCR-ELISA for detection of peste-des-petits-ruminants virus in clinical samples. Acta Virol. 2004;48:249-55.

24. Saravanan P, Balamurugan V, Sen A, Sreenivasa BP, Singh RP, Bandyopadhyay SK, Singh RK. Immune response of goats to a vero cell adapted live attenuated homologous PPR vaccine. Indian Vet J. 2010;87:1-3.

25. Sarkar J, Sreenivasa BP, Singh RP, Dhar P, Bandyopadhyay SK. Comparative efficacy of various chemical stabilizers on the thermostability of live attenuated peste des petits ruminants (PPR) vaccine. Vaccine. 2003;21:4728-35.

26. Shaila MS, Purushothaman V, Bhavasar D, Venugopal K, Venkatesan RA. Peste des petits ruminants of sheep in India. Vet Rec. 1989;1989(125):602.

27. Siddappa M, Gandam RK, Sarsani V, Mishra BP, Mishra B, Joshi CG, Sahoo AP, Tiwari AK, Janga SC. Whole-genome sequence of Sungri/96 vaccine strain of peste des petits ruminants virus. Genome Announc. 2(1):e0056-14. doi:10.1128/genomeA. 00056-14.2014.

28. Singh RP. Control strategies for peste des petits ruminants in small ruminants of India. Rev Sci Tech Off Int Epizoot. 2011;30:879-87.

29. Singh RP. Strategic control of peste des petits ruminants. In: Ranjan Garg, editor. Veterinary and livestock sector: a blueprint for capacity building Sudhi. New Delhi: Satish Serial Publisher; 2012. p. 327-45.

30. Singh RP, Saravanan P, Sreenivasa BP, Singh RK, Bandyopadhyay SK. Prevalence and distribution of peste des petits ruminants (PPR) virus infection in small ruminants of India. Rev Sci Tech Off Int Epizoot. 2004;23:807-19.

31. Singh RP, Sreenivasa BP, Dhar P, Shah LC, Bandyopadhyay SK. Development of monoclonal antibody based competitive-ELISA for detection and titration of antibodies to peste des petits ruminants virus. Vet Microbiol. 2004;98:3-15.

32. Singh RP, Sreenivasa BP, Dhar P, Bandyopadhyay SK. A sandwich ELISA for the diagnosis of peste des petits ruminants (PPR) infection in small ruminants using anti-nucleocapsid protein monoclonal antibody. Arch Virol. 2004;149:2155-70.

33. Singh RP, Bandyopadhyay SK, Sreenivasa BP, Dhar P. Production and characterization of monoclonal antibodies to peste des petits ruminants (PPR) virus. Vet Res Commun. 2004;28:623-39.

34. Singh RK, Balamurugan V, Bhanuprakash V, Sen A, Saravanan P, Yadav MP. Possible control and eradication of peste des petits ruminants from India: technical aspects. Vet Ital. 2009;45:449-62.

35. Singh RP, De UK, Pandey KD. Virological and antigenic characterization of two peste des petits ruminants (PPR) vaccine viruses of Indian origin. Comp Immunol Microbiol Infect Dis. 2010;33:343-53.

36. Sreenivasa BP, Dhar P, Singh RP, Bandyopadhyay SK. Evaluation of an indigenously developed homologous live attenuated cell culture vaccine against peste des petits ruminants infection of small ruminants. Presented at XX annual conference of Indian association of veterinary microbiologists, immunologists and specialists in infectious diseases and National symposium on trends in vaccinology for animal diseases. Pantnagar, India, 2000. p. 84 . 